\title{
How could chemical engineering help in deciphering electro- microbial mechanisms?
}

\author{
Alain Bergel ${ }^{1, a}$ \\ ${ }^{1}$ CNRS - Laboratoire de Génie Chimique (Chemical Engineering Centre) 4 allée Emile Monso, 31432 Toulouse, \\ France
}

\begin{abstract}
Electroactive microbial biofilms constitute a still-new research area of bioelectrochemistry, which proposes experimental systems that are original relative to those that have been studied for decades. In bioelectrochemistry, the interface is generally designed by the experimentalist, sometimes by using sophisticated surface modification protocols, in order to immobilize the biological component on the electrode surface in the best possible way. In contrast, in the case of electroactive biofilms, microorganisms do the work. The microbial cells produce slime that glues them to the electrode surface and forms complex biofilm/electrode interfaces, on which the experimentalist has very few action levers. In this context, chemical engineering methods can be very helpful to decipher the numerous interacting steps that control electron transfer and also to scale up the interfaces to actual applications.
\end{abstract}

Electron transfer (ET) inside biofilms can occur through several direct and indirect pathways, which have been detailed elsewhere [1]. Electroactive biofilms can ensure fast electrochemical kinetics, close to reversible (Nernstian) ET. When biofilms display less efficient global kinetics, it is generally assumed that ET between the electrode and the redox biological compounds is not Nernstian. In contrast, it has recently been demonstrated that non-Nernstian global kinetics can be due to the presence of different ET pathways, each following a Nernstian type but around a different redox potential [2]. When this hypothesis is valid, the way to improve the biofilm electroactivity is no longer to try to enhance the ET rate between the electrode and the different redox compounds, but to drive the biofilm towards the production of the most efficient redox compounds. For example, growing an electroactive biofilm around ultra-microelectrodes has been shown to be an excellent way to improve the ET capability of the biofilm matrix, raising current density from 7 to $65 \mathrm{~A} / \mathrm{m} 2$ on fully flat electrode surfaces [3].

The nagging problem of scaling-up microbial electrochemical technologies is addressed in the second part of the presentation, starting with microbial fuel cells (MFC). Ideally, a microbial anode works at close-to-neutral $\mathrm{pH}$, while an abiotic O2-reducing cathode should work at acidic $\mathrm{pH}$. The $\mathrm{pH}$

\footnotetext{
${ }^{\text {a }}$ Corresponding author: alain.bergel@ensiacet.fr
} 
gradient is a problem that it is essential to tackle in the objective of scaling-up efficient MFCs. In this context, ion transport through the bulk is a main limiting step, which deserves deeper investigation. In particular, when the objective is to maximize the power produced, proton transport should no longer be considered because it plays no significant electricity-carrying role in the electrolyte.

The importance of ionic conductivity is illustrated on the case of microbial electrolysis cells for hydrogen production. The thermodynamic advantage related to the use of a microbial anode can be completely lost if low ionic conductivity of the electrolyte induces a high ohmic drop. To overcome this drawback, halotolerant microbial anodes have been developed, which produce up to $80 \mathrm{~A} / \mathrm{m} 2$ in electrolytes that contain $45 \mathrm{~g} / \mathrm{L} \mathrm{NaCl}$, resulting in a conductivity of $10.4 \mathrm{~S} . \mathrm{m}-1$ [4,5]. Finally, a brief incursion into the mechanisms of $\mathrm{CO} 2$ reduction on a microbial cathode is proposed, showing the importance of the hydrogen route [6]. With the objective of scaling-up commercial electrosynthesis cells, the high current densities required to ensure economic efficiency would favour strong hydrogen evolution on the cathode and preclude biofilm formation on the electrode surface. In this context, microbial reduction of $\mathrm{CO} 2$ in gas-liquid reactors provided with hydrogen is a promising way to move the fundamental advances made in microbial electrosynthesis towards industrial applications.

\section{References}

1- H. Richter, K.P. Nevin, H. Jia, D.A. Lowy, D.R. Lovley, L.M. Tender, Energy Environ. Sci. 2, 506 (2009).

2- M. Rimboud, E. Desmond-Le Quemeneur, B. Erable, T. Bouchez, A. Bergel, Bioresource Technol. 195, 162 (2015).

3- D. Pocaznoi, B. Erable, M.-L. Délia, A. Bergel, Energy Environ. Sci. 5, 5287 (2012).

4- R. Rousseau, X. Dominguez, M.-L. Délia, A. Bergel, Electrochem. Commun. 33, 1 (2013).

5- R. Rousseau, C. Santaella, W. Achouak, J.-J. Godon, A. Bonnafous, A. Bergel, M.-L. Délia, ChemElectroChem 1, 1966 (2014).

6- E. Blanchet, F. Duquenne, Y. Rafrafi, L. Etcheverry, B. Erable, A. Bergel. Sci. 8, 3731 (2015). 